\title{
O processo de fabricação de papel reciclado e as ações associadas aos custos ambientais em indústria de Santa Catarina
}

Alessandra Vasconcelos Gallon
Mestrado em Ciências Contábeis pela Universidade Regional de Blumenau - FURB
Rua Antônio da Veiga, B. Victor Konder, 140. Blumenau/SC. CEP: 89012-900

E-mail: alegallon@sodisa.com.br

Franciane Luiza Salamoni

Mestrado em Ciências Contábeis pela Universidade Regional de Blumenau - FURB Rua Antônio da Veiga, B. Victor Konder, 140. Blumenau/SC. CEP: 89012-900

E-mail: fransalamoni@gegnet.com.br

Ilse Maria Beuren

Doutorado em Controladoria e Contabilidade pela FEA/USP Rua Antônio da Veiga, B. Victor Konder, 140. Blumenau/SC. CEP: 89012-

900

E-mail: ilse@furb.br

\section{RESUMO}

A crescente preocupação com a preservação ambiental requer a eliminação e/ou redução dos efeitos negativos do processo de produção industrial. Nesta perspectiva, o artigo objetiva descrever o processo de fabricação de papel reciclado e identificar ações executadas pela empresa associadas aos custos ambientais. Para tanto, fez-se uma pesquisa exploratória, por meio de um estudo de caso em indústria catarinense, com abordagem qualitativa dos dados. Como resultado da pesquisa tem-se que o processo de fabricação inicia com a adição das matérias-primas, passa pela desagregação e refinação da massa, segue para a suspensão fibrosa e finaliza com a secagem e rebobinamento do papel para avaliação de sua qualidade. $O$ tratamento dado aos resíduos pela indústria de reciclagem contribui para a preservação ambiental, uma vez que quase sua totalidade retorna ao processo fabril de papel sob forma de matéria-prima. Conclui-se que a sua ação pró-ativa à gestão de custos ambientais é promitente em termos de prevenção de danos ambientais e conseqüentemente em redução de custos.

Palavras-chave: Tratamento dos resíduos. Papel reciclado. Custos ambientais.

The manufacturing process of recycled paper and actions associated with environmental costs to industry in the state of Santa Catarina

\section{ABSTRACT}

The growing concern with environmental preservation requires the reduction and/or 
O processo de fabricação de papel reciclado e as ações associadas aos custos ambientais em indústria de Santa Catarina

Alessandra Vasconcelos Gallon, Franciane Luiza Salamoni, Ilse Maria Beuren

elimination of negative effects resulting from industrial production processes. In light of this, the article sets out to describe the process involved in the fabrication of recycled paper and to identify actions taken by business associated with environmental costs. To do so, an exploratory study was made, by means of a case study of a Santa Catarina industry, using a qualitative approach with the data. One result of the research was to ascertain that the fabrication process begins with the addition of raw materials, passes through breakdown and refining of pulp, followed by fibrous suspension, and ends with the drying and re- rolling of the paper in order to evaluate its quality. The treatment given to waste materials by the recycling industry contributes to environmental preservation since almost all of it goes back into the industrial process of making paper, in the form of raw material. The study concluded that this figures prominently as a pro-active function to environmental cost management in terms of prevention of environmental damage and, consequently, contributes to a reduction in costs.

Key words: Treatment of waste materials. Recycled paper. Environmental Costs.

\section{INTRODUÇÃO}

Embora importantes movimentos de regulamentação de políticas ambientais já tenham ocorrido na década de 1930, somente por volta do final da década de 1960 aumentou a preocupação com o meio ambiente. É importante observar que o ambientalismo não possui uma data de nascimento determinada, mas tentar encontrar suas raízes consiste principalmente na necessidade de se ter explicações para sua crescente importância (Duarte, 1997).

Deflagrados os limites do sistema ecológico, a sociedade, governos e empresários começaram a demonstrar sua preocupação com os limites do meio ambiente, com a capacidade de continuar reagindo aos crescentes níveis de impurezas que the são acrescidos diariamente (Ribeiro, 1992).

Nesta perspectiva e diante da crescente disseminação das informações propiciadas pelas novas tecnologias de comunicação, as indústrias estão sendo forçadas a tomar posições diferenciadas com relação às estratégias de mercado nas últimas décadas. Algumas preocupações com os aspectos sociais nas indústrias podem ser salientadas, especialmente com relação às questões ambientais.

Gobbi e Brito (2005) destacam que os debates em torno da questão ambiental ganharam expressa legitimidade social a ponto de se tornar objeto de reflexão das 
O processo de fabricação de papel reciclado e as ações associadas aos custos ambientais em indústria de Santa Catarina Alessandra Vasconcelos Gallon, Franciane Luiza Salamoni, Ilse Maria Beuren

organizações, que passaram a repensar suas práticas de produção e a formular políticas de gestão ambiental.

A parceria construída entre indústria e fornecedores desenvolve-se em função das exigências de novas tecnologias que atendam ao aumento na escala de produção, ao comprometimento com a preservação ao meio ambiente, à economia de energia e insumos e à redução dos custos, de acordo com a Associação Brasileira Técnica de Celulose e Papel - ABTCP (2004).

Entretanto, ao que tudo indica a eliminação dos resíduos provenientes do papel e celulose pode não estar tendo o destino adequado para a preservação do meio ambiente. Diante disso, surgem algumas indagações incentivadoras da pesquisa: Como se dá o processo de fabricação de papel reciclado? O tratamento dado aos resíduos nas indústrias de papel reciclado focaliza a preservação do meio ambiente? Quais as ações associadas aos custos ambientais são executadas pela empresa?

Visando responder a essas questões, o artigo objetiva descrever o processo de fabricação de papel reciclado e identificar ações executadas pela empresa associadas aos custos ambientais. A relevância da pesquisa evidencia-se na medida em que se verifica uma crescente preocupação com a preservação ambiental no mundo, principalmente no que se refere ao descontrole dos desmatamentos e à poluição do meio ambiente. Também se observa esforços de organizações para minimizar os efeitos da devastação de recursos, sejam eles recuperáveis ou não.

Quanto à organização do trabalho, ele inicia com uma breve abordagem sobre o surgimento e importância do papel, seguida de um apanhado teórico sobre reciclagem e meio ambiente, e trata da gestão de custos ambientais. Na sequência, evidencia o método e os procedimentos de pesquisa adotados. Em seguida faz a descrição e análise dos dados coletados na empresa objeto de estudo. Por último, apresenta as conclusões da pesquisa. 
O processo de fabricação de papel reciclado e as ações associadas aos custos ambientais em indústria de Santa Catarina

Alessandra Vasconcelos Gallon, Franciane Luiza Salamoni, Ilse Maria Beuren

\section{PRODUÇÃO E CONSUMO DE PAPEL}

A invenção da escrita é considerada o fator motivador e modificador das lentas, mas constantes, evoluções e alterações pelas quais passaram diversas bases (pedra, cerâmica, madeira, ossos, fios de tecidos, couro curtido e os metais e suas ligas, como o bronze), até se chegar ao papel. Foi o papiro que deu origem à palavra papel, do latim papyrus (ABTCP, 2004).

De acordo com dados da ABTCP (2004), em 2002, a extração brasileira de celulose foi de 8 milhões de toneladas, o que significou um crescimento de $7,9 \% \mathrm{em}$ relação ao índice observado em 2001. Por sua vez o consumo de papel cresceu 1,2\% se comparado com o exercício anterior, chegando a um total de 6,8 milhões de toneladas, o equivalente a 38 quilos anuais per capita.

Conforme a ABTCP (2004), seja qual for o tipo de papel fabricado, a matériaprima básica é a celulose, virgem ou de papel reciclado, que pode ser dividida em dois grupos: a de fibra longa (obtida de espécies como o pínus e a araucária), indicada para papéis de embalagem; e a de fibra curta (derivada de eucalipto, acácia, gmelina, bétula, entre outros), utilizada principalmente na fabricação de papéis para imprimir e escrever e para fins sanitários.

A Associação Brasileira de Celulose e Papel (BRACELPA, 1998) ressalta que entre os papéis consumidos, o maior destaque é para as caixas de papelão ondulado, pois funcionam como embalagem de transporte para a quase totalidade das mercadorias comercializadas em supermercados, lojas de departamento (magazines) e estabelecimentos fabris. Também são gerados resíduos de caixas de papelão ondulado nas residências, especialmente as que servem de embalagem de acondicionamento de eletrodomésticos. Em 1997, segundo dados daquela associação, 61,6\% dos papéis recuperados no Brasil são de "papel ondulado".

De acordo com o World Business Council for Sustainable Development WBCSD (1996), a produção de papel consome enorme quantidade de energia e água. Destaca-se que em 1992 a indústria papeleira americana foi a terceira maior 
O processo de fabricação de papel reciclado e as ações associadas aos custos ambientais em indústria de Santa Catarina

Alessandra Vasconcelos Gallon, Franciane Luiza Salamoni, Ilse Maria Beuren

consumidora de energia, ficando atrás apenas da indústria do petróleo e do setor químico. A água é um ingrediente essencial na fabricação de papel como parte integrante da massa (polpa) e utilização na remoção de impurezas da celulose mediante lavagens repetidas, sendo que a emissão de efluentes na água é um dos impactos ambientais mais significantes causados pela fabricação de papel e celulose (WBCSD, 1996).

Entretanto, destaca-se que novas tecnologias tornaram possível o maior fechamento do ciclo de água, o que reduziu a geração de efluentes. A indústria de papel e celulose tem investido sobremaneira em tecnologia de reutilização (ABTCP, 2004). De acordo com a Divisão de Tecnologia Industrial do Departamento de Assistência à Média e Pequena Indústria (DETEC), a indústria de papel e celulose caracteriza-se como moderada geradora de resíduos sólidos de baixo poder impactante e elevada potencialidade de utilização.

No entanto, Nossa e Carvalho (2003) citam dois estudos que consideram esse setor altamente poluidor. Destacam que Cormier e Magnan (1997) apontam o setor de papel e celulose como um dos setores que mais polui. Reforçam esse posicionamento com Forgach (2001), que apresenta razões para que a indústria de papel e celulose seja assim considerada: a) é dependente de $100 \%$ de fibras florestais naturais e recicladas; b) exige uso intensivo de energia; c) emite no ar, água e terra ampla gama de poluentes tóxicos e convencionais; d) é grande produtora de resíduo sólido.

Em relação ao primeiro item apontado por Forgach (2001 in Nossa e Carvalho, 2003), a indústria de papel reciclado tem menor impacto na extração de fibras florestais naturais porque utiliza material reciclado. Os demais itens citados também são inerentes ao seu processo produtivo. Portanto são contingências que precisam ser monitoradas por essas indústrias em relação ao meio ambiente.

\section{RECICLAGEM E MEIO AMBIENTE}

A conscientização sobre os problemas que afetam o meio ambiente age como fator preponderante para compatibilizar a expansão dos meios de produção de acordo 
O processo de fabricação de papel reciclado e as ações associadas aos custos ambientais em indústria de Santa Catarina Alessandra Vasconcelos Gallon, Franciane Luiza Salamoni, Ilse Maria Beuren

com condições ambientais ideais. A responsabilidade social da empresa deveria voltarse para a eliminação e/ou redução dos efeitos negativos do processo de produção e preservação dos recursos naturais, principalmente os não renováveis, através da adoção de tecnologias eficientes, concomitantemente ao atendimento dos aspectos econômicos (Ribeiro, 1992).

O aumento da conscientização ambiental tem levado a uma maior demanda por papéis reciclados e a pressionar para que o papel seja reciclado após sua utilização pelo público (resíduo após o consumo), ao invés de simplesmente jogá-lo nos aterros (WBCSD, 1996). Rossato e Ribeiro (2004, p. 62) destacam que "têm aumentado, consideravelmente, nos últimos anos, as discussões sobre qual a melhor forma para que as empresas conciliem seus processos produtivos com questões ambientais".

Segundo Andrade et al. (2002), os gastos com proteção ambiental começam a ser vistos pelas empresas líderes, não primordialmente como custos, mas como investimentos no futuro e, paradoxalmente, como vantagem competitiva. Para Hunt e Auster (1990) e Hart (1995), melhores performances ambientais e econômicas podem coexistir por meio da incorporação de um novo modelo de organização e de uma cultura empresarial baseada na ecoeficiência, o que conduzirá a um desenvolvimento sustentável.

Ribeiro (1992) comenta que a incorporação do conceito de "desenvolvimento sustentável" pelo meio empresarial pode, se não reverter, ao menos amenizar a degradação do meio ambiente. Na perspectiva do desenvolvimento sustentável, a redução de agressões ambientais passa a ser considerada como meio de eliminação de custos e conseqüente melhoria do fluxo de rendimentos para a empresa.

Nesse sentido, mesmo não se tratando de uma novidade no processo de fabricação do papel, pois há séculos os materiais utilizados (aparas) têm sido reaproveitados na fabricação de novos produtos, a reciclagem é um importante aspecto da filosofia preservacionista, que resulta em benefícios tanto para as empresas como para a coletividade (ABTCP, 2004).

A reciclagem de papel no Brasil tem seu fundamento em questões de natureza 
O processo de fabricação de papel reciclado e as ações associadas aos custos ambientais em indústria de Santa Catarina

Alessandra Vasconcelos Gallon, Franciane Luiza Salamoni, Ilse Maria Beuren

essencialmente econômicas. Todavia esta vem apresentando um destaque crescente, na medida em que contribui para a preservação e conservação do meio ambiente e para a solução da questão da destinação dos lixos urbanos (BRACELPA, 1998).

Quanto à importância da utilização da reciclagem na indústria de papel e celulose como forma de minimizar os impactos ao meio ambiente, Bellia (1996) relata que a reciclagem de papel leva a uma redução de energia para a produção de papel e celulose da ordem de $23 \%$ a $74 \%$, redução na poluição do ar de $74 \%$, redução na poluição da água em torno de $35 \%$ e redução de $58 \%$ no uso de água.

Robles Jr. (2003, p. 139) destaca que "a solução dos problemas ambientais é consequência da existência de um sistema de gestão ambiental bem administrado, para identificação clara dos problemas e suas causas". Nesta perspectiva, torna-se imprescindível que a empresa desfrute de adequada gestão de custos ambientais.

\section{GESTÃO DE CUSTOS AMBIENTAIS}

Campos (1996) salienta que o termo custo ambiental é de difícil conceituação, não apresentando definição clara e objetiva, e que a maior dificuldade ao se trabalhar com custos ambientais é o fato de estes serem, em sua maioria, custos intangíveis. Robles Jr. (2003, p. 141) define custos intangíveis como "aqueles com alto grau de dificuldade para serem quantificados, embora se perceba claramente a sua existência. Normalmente não podem ser diretamente associados ao produto ou processo".

No que diz respeito aos gastos ambientais, Ribeiro e Rocha (1999, p. 2) relatam que "são todos aqueles relacionados, direta ou indiretamente, ao processo de gerenciamento ambiental, processo este que compreende todas as atividades inerentes ao controle, preservação e proteção ao meio ecológico, além de recuperação de áreas contaminadas".

Ferreira et al. (2007, p. 28) advertem que "uma empresa que polui dentro dos limites legais estabelecidos não deixa de ter um passivo em relação ao meio ambiente, pois haverá a necessidade de restaurar ou remediar o meio ambiente, ou seja, poderá 
haver uma obrigação pecuniária". Esta obrigação, seja ela de reputação social ou exigência legal, implica em um custo ambiental para a empresa.

Nos custos ambientais devem ser computadas todas as medidas tomadas pelos gestores da entidade com a finalidade de evitar, reduzir ou reparar efeitos ambientais negativos. Devem considerar-se essas medidas, sejam elas necessárias ao cumprimento de determinação legal; ou decorrentes de medidas voluntárias da entidade, para responder às exigências de clientes, ou melhorar a imagem da entidade (Eurostat in Silva, 2007).

Segundo Hansen e Mowen (2001, p. 567), sob o ponto de vista empresarial, os custos ambientais, também conhecidos como custos de qualidade ambiental, "são custos incorridos porque existe uma má qualidade ambiental ou porque pode existir uma má qualidade ambiental".

Em função das mudanças na relação entre empresas e o meio ambiente, observa-se a importância da identificação dos custos ambientais pelas empresas para a consecução de informações consistentes relativas ao quanto se vem perdendo ou deixando de ganhar com processos e atividades que degradam o meio ambiente.

De acordo com a Federação e Centro das Indústrias do Estado de São Paulo FIESP (2004), a melhoria na relação da empresa com o meio ambiente é capaz de otimizar a produtividade dos recursos utilizados, implicando em benefícios diretos para a empresa, o processo industrial e o produto, como mostra o Quadro 1. 
O processo de fabricação de papel reciclado e as ações associadas aos custos ambientais em indústria de Santa Catarina

Alessandra Vasconcelos Gallon, Franciane Luiza Salamoni, Ilse Maria Beuren

\begin{tabular}{|c|c|c|}
\hline Benefícios para a empresa & $\begin{array}{r}\text { Benefícios para o } \\
\text { processo }\end{array}$ & Benefícios para o produto \\
\hline $\begin{array}{c}\text { - } \quad \text { melhoria da imagem da } \\
\text { empresa; } \\
\text { - } \quad \text { manutenção dos atuais e } \\
\text { conquista de novos nichos } \\
\text { de mercado; } \\
\text { - } \quad \text { redução do risco de } \\
\text { desastres ambientais; } \\
\text { - adição do valor com a } \\
\text { eliminação ou minimização } \\
\text { dos resíduos; } \\
\text { - menor incidência de custos } \\
\text { com multas e processos } \\
\text { judiciais; e } \\
\text { maior diálogo com os } \\
\text { órgãos de controle e } \\
\text { fiscalização. }\end{array}$ & $\begin{array}{l}\text { - } \quad \text { economias de matéria-prima } \\
\text { e insumos, resultantes do } \\
\text { processamento mais } \\
\text { eficiente e da sua } \\
\text { substituição, reutilização e } \\
\text { reciclagem; } \\
\text { - } \quad \text { aumento dos rendimentos do } \\
\text { processo produtivo; } \\
\text { - } \quad \text { redução das paralisações, } \\
\text { por meio de maior cuidado } \\
\text { na monitoração e } \\
\text { manutenção; } \\
\text { - melhor utilização dos } \\
\text { subprodutos; } \\
\text { - conversão dos desperdícios } \\
\text { em forma de valor; } \\
\text { menor consumo de água e } \\
\text { energia durante o processo; } \\
\text { economia, em razão de um } \\
\text { ambiente de trabalho mais } \\
\text { seguro; e } \\
\text { eliminação ou redução do } \\
\text { custo de atividades } \\
\text { envolvidas nas descargas ou } \\
\text { no manuseio, transporte e } \\
\text { descarte de resíduos. }\end{array}$ & $\begin{array}{l}\text { - } \quad \text { mais qualidade } \\
\text { e uniformidade; } \\
\text { - } \quad \text { redução dos custos (por } \\
\text { exemplo, com a } \\
\text { substituição de materiais); } \\
\text { - } \quad \text { redução nos custos de } \\
\text { embalagens; } \\
\text { - } \quad \text { utilização mais eficiente } \\
\text { dos recursos; } \\
\text { - } \quad \text { aumento da segurança; } \\
\text { - } \quad \text { redução do custo líquido } \\
\text { do descarte pelo cliente; e } \\
\text { - maior valor de revenda e } \\
\text { de sucata do produto. }\end{array}$ \\
\hline
\end{tabular}

Quadro 1 - Benefícios causados pela melhoria na relação entre a empresa e o meio ambiente Fonte: Cartilha de indicadores de desempenho ambiental na indústria - FIESP (2004, p. 13).

Depreende-se que a melhoria na relação entre a empresa e o meio ambiente traz diversos benefícios para ambos com a gestão do desperdício, o controle da poluição, gestão da água e da energia, obediência às leis, entre outros.

As informações dos custos ambientais relacionados aos processos servem como indicativo no sentido de propor melhorias para diminuir ou até mesmo eliminar tais custos, gerando vantagem para a empresa. Quanto ao meio ambiente, com a identificação dos custos ambientais, poder-se-ia propor melhorias nos processos que resultem na diminuição do dano causado ao meio ambiente, beneficiando o meio ambiente (Campos, 1996).

Para Moura (2000, p. 49-50 in Robles Jr, 2003, p. 139), "os custos da qualidade 
ambiental podem ser considerados de dois tipos: custos de controle e custos resultantes da falta de controle sobre os processos industriais e gerenciais". A Figura 1 demonstra a identificação dos custos ambientais de acordo com a classificação do autor.
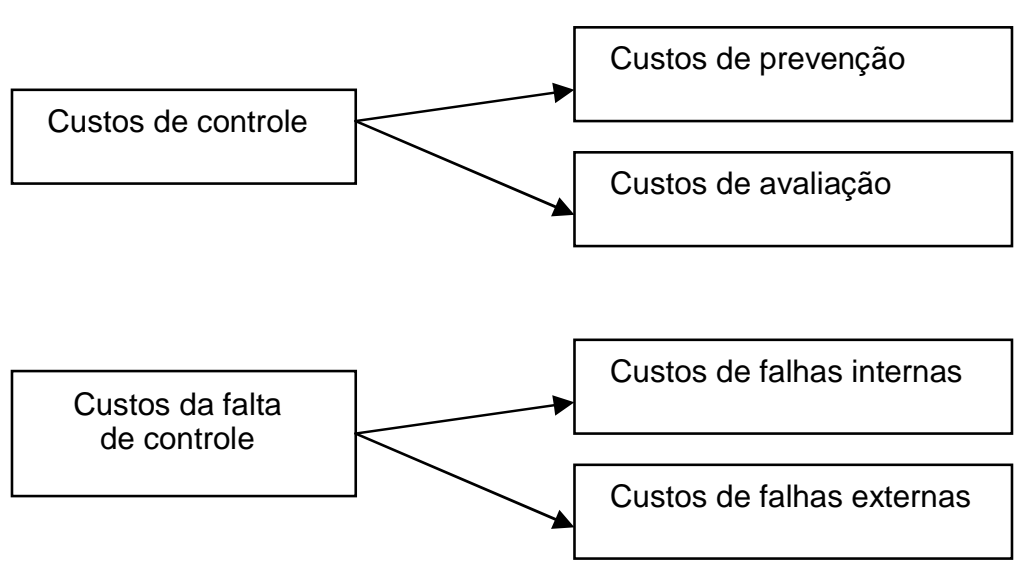

Figura 1- Identificação dos custos ambientais Fonte: Robles Júnior (2003, p. 140).

Os custos ambientais, dessa forma, estão associados com a criação, detecção, correção e prevenção da degradação ambiental. Os custos de controle podem ser classificados em custos de prevenção e custos de avaliação ou de detecção; e os custos da falta de controle, classificados em custos de falhas internas e de falhas externas.

Graedel e Allenby (1996, p. 318) conceituam os custos de prevenção ambiental como "o uso de materiais, processos, ou práticas que reduzam ou eliminem a quantidade ou toxidade de resíduos na fonte de geração através de atividades que promovam, encorajam ou exijam modificações nos padrões comportamentais básicos da empresa". Esses autores consideram a prevenção como algo muito mais viável para a indústria do que o controle e a correção.

Com relação à viabilidade da ênfase nos custos ambientais de prevenção em detrimento dos custos ambientais da falta de controle, Hansen e Mowen (2001, p. 564- 
O processo de fabricação de papel reciclado e as ações associadas aos custos ambientais em indústria de Santa Catarina Alessandra Vasconcelos Gallon, Franciane Luiza Salamoni, Ilse Maria Beuren

565) defendem que "uma abordagem pró-ativa é mais promissora em termos de prevenção de danos ambientais e, simultaneamente, em redução de custos". Complementam mencionando que "reguladores e empresas estão começando a perceber que pode ser menos oneroso prevenir a poluição do que remediá-la".

São exemplos de atividades de prevenção ambiental, segundo Hansen e Mowen (2001): avaliação e seleção de fornecedores, avaliação e seleção de equipamentos de controle da poluição, projeção de processos e produtos para reduzir ou eliminar os contaminadores, treinamento de empregados, estudo dos impactos ambientais, auditoria dos riscos ambientais, execução de pesquisas ambientais, desenvolvimento de sistemas de gestão ambiental, reciclagem de produtos e obtenção do certificado ISO 14001.

No que tange aos custos de avaliação ou detecção ambiental, Robles Jr. (2003, p. 140) afirma que "são custos despendidos para manter os níveis de qualidade ambiental da empresa, por meio de trabalhos de laboratórios e avaliações formais do sistema de gestão ambiental ou sistema gerencial, que se ocupem de garantir um bom desempenho ambiental da empresa". Estes custos são incorridos ao verificar se os processos e produtos da empresa estão cumprindo as normas ambientais apropriadas.

Hansen e Mowen (2001) exemplificam as seguintes atividades como de avaliação e deteç̧ão ambiental: auditorias ambientais, inspeção de produtos e processos (para averiguar a conformidade ambiental), o desenvolvimento de medidas de desempenho ambiental, a execução de testes de contaminação, a verificação do desempenho ambiental de fornecedores e a medição de níveis de contaminação.

Com relação aos custos da falta de controle, estes podem ser de falhas ambientais internas (custos incorridos pelo não-atendimento de normas, padrões, procedimentos operacionais explícitos de gestão ambiental e correções de nãoconformidades) e de falhas ambientais externas (custos da qualidade ambiental insatisfatória e não-conformidades fora dos limites da empresa, resultantes de uma gestão ambiental inadequada) (Robles Jr., 2003).

São exemplos de atividades de falhas internas, segundo Hansen e Mowen 
O processo de fabricação de papel reciclado e as ações associadas aos custos ambientais em indústria de Santa Catarina

Alessandra Vasconcelos Gallon, Franciane Luiza Salamoni, Ilse Maria Beuren

(2001): operação de equipamento para minimizar ou eliminar poluição, tratamento e descarte de materiais tóxicos, manutenção de equipamento para poluição, licenciamento de instalações para a produção de contaminantes, retrabalhos em processos causados por não-conformidade ambiental e reciclagem de sucata.

De acordo com Hansen e Mowen (2001), os custos de falhas ambientais externas podem ser classificados em: custos realizados de falhas externas (custos incorridos e pagos pela empresa) e custos não-realizados de falhas externas (custos sociais causados pela empresa, mas incorridos e pagos por parte fora da empresa).

São exemplos de atividades realizadas de falhas externas, segundo Hansen e Mowen (2001): limpeza de um rio ou lago poluído, limpeza de solo contaminado, uso ineficiente de materiais e energia, indenização por acidentes pessoais provenientes de más práticas ambientais, restauração da terra ao estado natural e perda de vendas causada por uma má reputação ambiental.

Os exemplos de custos sociais, segundo os autores, incluem: receber cuidados médicos por causa do ar poluído, perder empregos por causa de contaminação, perder um rio ou lago de uso recreativo por causa da contaminação e danificar ecossistemas devido ao descarte de resíduos sólidos.

Diante do exposto, observa-se que a utilização pelas empresas de medidas eficazes para a qualidade ambiental, identificando e buscando reduzir ou eliminar os custos ambientais (de controle, correção e falhas existentes) e priorizando os custos de prevenção ambiental, minimiza a ocorrência das falhas relacionadas ao processo produtivo e ao meio ambiente.

\section{MÉTODO E PROCEDIMENTOS DA PESQUISA}

O método empregado na presente pesquisa é de natureza exploratória, a qual foi realizada por meio de um estudo de caso, com abordagem qualitativa dos dados. Para Cervo e Bervian (1996), a pesquisa exploratória é responsável por observar, registrar, analisar e correlacionar os fatos ou fenômenos sem manipulá-los. 
O processo de fabricação de papel reciclado e as ações associadas aos custos ambientais em indústria de Santa Catarina Alessandra Vasconcelos Gallon, Franciane Luiza Salamoni, Ilse Maria Beuren

O estudo de caso foi realizado em uma indústria de papel e celulose estabelecida no Estado de Santa Catarina, cuja denominação social declina-se revelar por motivos de sigilo das estratégias da organização. O estudo de caso permite uma investigação para se preservar as características holísticas e significativas dos eventos da vida real (Yin, 2003).

Quanto aos procedimentos de coleta de dados, realizada em abril de 2006, optou-se por adotar, inicialmente, entrevista semi-estruturada com o gerente de produção da empresa e duas pessoas encarregadas dos aspectos relacionados ao meio ambiente na empresa. Segundo Triviños (1987), a entrevista semi-estruturada é a que parte de certos questionamentos básicos, apoiados no referencial teórico e hipóteses, que provocam novos questionamentos no transcorrer da entrevista e influenciam a elaboração do conteúdo da pesquisa.

Para melhor compreensão do processo de produção da indústria utilizou-se também a técnica de observação. Sobre o método observacional, Fachin (2001) adverte que o observador deve reunir certas condições, entre as quais: dispor dos órgãos sensoriais em perfeito estado, de um bom preparo intelectual, aliado à sagacidade, curiosidade, persistência, perseverança, paciência e um grau elevado de humildade.

Quanto aos procedimentos sistemáticos para a descrição e explicação dos fenômenos, o estudo desenvolveu-se num ambiente que preconizou a abordagem qualitativa. O método qualitativo, conforme Richardson (1999), se caracteriza pelo não emprego de instrumental estatístico como base no processo de análise de um problema. Para os dados coletados nas entrevistas foi adotada a análise de conteúdo ou content analysis (Bardin, 2006).

Embora tenha sido adotado o rigor científico necessário em pesquisa dessa natureza, ressalta-se o fato do estudo se circunscrever a um único objeto ou fenômeno. Esta estratégia de pesquisa se constitui em uma limitação, uma vez que seus resultados não podem ser generalizáveis a outros objetos ou fenômenos, dado as particularidades do sujeito da pesquisa. 
O processo de fabricação de papel reciclado e as ações associadas aos custos ambientais em indústria de Santa Catarina

Alessandra Vasconcelos Gallon, Franciane Luiza Salamoni, Ilse Maria Beuren

\section{DESCRIÇÃO DO PROCESSO DE FABRICAÇÃO DO PAPEL RECICLADO E AÇÕES ASSOCIADAS AOS CUSTOS AMBIENTAIS DA EMPRESA PESQUISADA}

Para a compreensão da fabricação do papel reciclado realizou-se um estudo das operações em indústria de papel e celulose. Intenta-se mostrar os passos da fabricação do papel reciclado, desde a desagregação do papel velho e transformação da massa até a transformação da folha de papel, com a passagem nos secadores da máquina de papel. Focaliza-se, também, o tratamento dado pela empresa aos resíduos. Por fim, apresentam-se as ações associadas aos custos ambientais executadas pela empresa.

\subsection{Apresentação da empresa}

A indústria de papel e celulose objeto de estudo teve sua constituição na década de 1960, motivada pela preocupação com os elevados volumes de resíduos da atividade madeireira. Em 1977 iniciou os planos para a produção de papelão ondulado para embalagens e em 1978 deu início ao processo de fabricação do papelão ondulado reciclado na empresa.

Depreende-se o que já foi destacado na fundamentação teórica do estudo, de que a preocupação com a reciclagem de papel tem seu fundamento em questões de natureza essencialmente econômicas nas empresas, embora haja destaque crescente, atualmente, para a contribuição da preservação e conservação do meio ambiente (BRACELPA, 1998).

A empresa em foco tem como objeto social a transformação de resíduos da indústria da madeira e papel reciclado em papel ondulado (para embalagem de transporte). Sua produção abastece o grupo empresarial ao qual pertence e o restante da produção é consumido no mercado interno. Possui 160 empregados, apenas na fabricação do papel reciclado, pois o grupo empresarial, em todas as suas outras atividades relacionadas à indústria madeireira, gera em torno de 1.700 empregos e fatura anualmente um milhão de reais.

Para a compreensão do processo de fabricação do papel reciclado são 
apresentados três fluxos de operações. No primeiro fluxo são demonstradas as operações de fabricação desde a desagregação do papel velho até a transformação da massa. No segundo fluxo demonstra-se a transformação dos resíduos da indústria da madeira e papel reciclado em massa e hidratação das fibras. No terceiro fluxo mostrase a transformação do papel ondulado reciclado.

\subsection{Descrição do processo de fabricação do papel reciclado}

$\mathrm{Na}$ Figura 2 apresenta-se a etapa inicial do processo da fabricação do papel reciclado, desde a entrada da matéria-prima até a desagregação da mesma e transformação da massa.

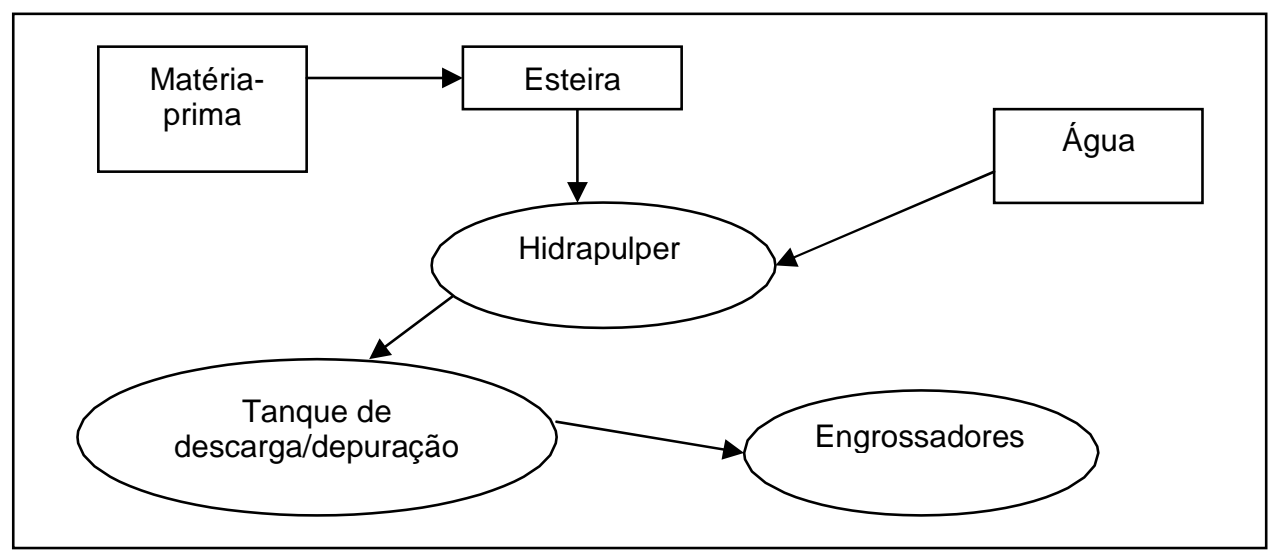

Figura 2 - Fabricação do papel reciclado desde a desagregação do papel velho até a transformação da massa

Fonte: dados da pesquisa.

O processo de fabricação do papel reciclado inicia-se com a colocação da matéria-prima em uma esteira, que a transporta até o equipamento denominado Hidrapulper onde é acrescido água e efetua-se a desagregação da matéria-prima. As matérias-primas utilizadas na fabricação do papel são basicamente aparas (papel reciclado), celulose e pasta químico- mecânica.

Depois da desagregação da matéria-prima, esta é recebida na forma de fardos que se transformam em pequenos pedaços de papel formando uma massa. Ressalta- 
se que no Hidrapulper a matéria-prima sofre também um processo de pré-depuração, com a finalidade de remover impurezas, como grampos, clipes, pedras, arames e plásticos.

Após a desagregação, a massa segue por meio de bombas por tubulações para um tanque de descarga e, em seguida, passa para o processo de depuração, que consiste em remover impurezas da massa, tais como: areia, plásticos, palitos, isopor e pastilhas de papel, que não se individualizam na desagregação.

$\mathrm{Na}$ sequência, a massa segue para o processo de transformação da massa e hidratação das fibras, conforme demonstrado na Figura 3. 


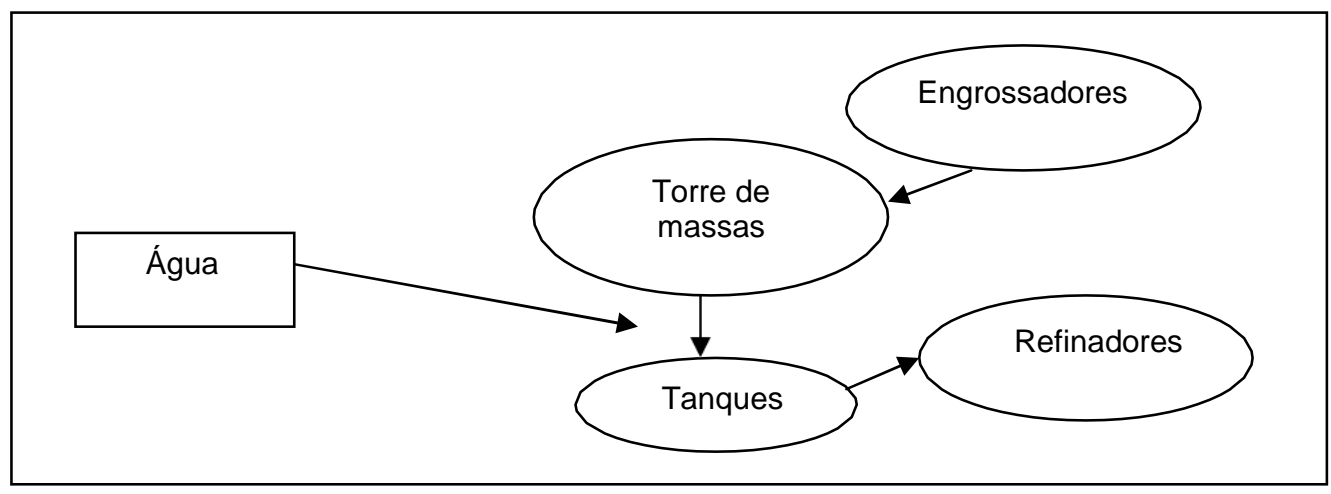

Figura 3 - Transformação da massa e hidratação das fibras

Fonte: dados da pesquisa.

Nesta fase, a depuração da massa segue para os engrossadores onde é extraída a água, e a consistência da suspensão fibrosa fica em torno de 5\% para posterior estocagem nas torres de massa. A massa é extraída das torres de massa e sofre adição de água para baixar a consistência, seguindo para os tanques, onde é extraída por meio de bombas para os equipamentos de refinação. Nos refinadores, a fibra sofre atrito de discos rotativos com lâminas de aço onde é hidratada. Na Figura 4 apresenta-se a etapa final do processo de fabricação do papel ondulado reciclado.

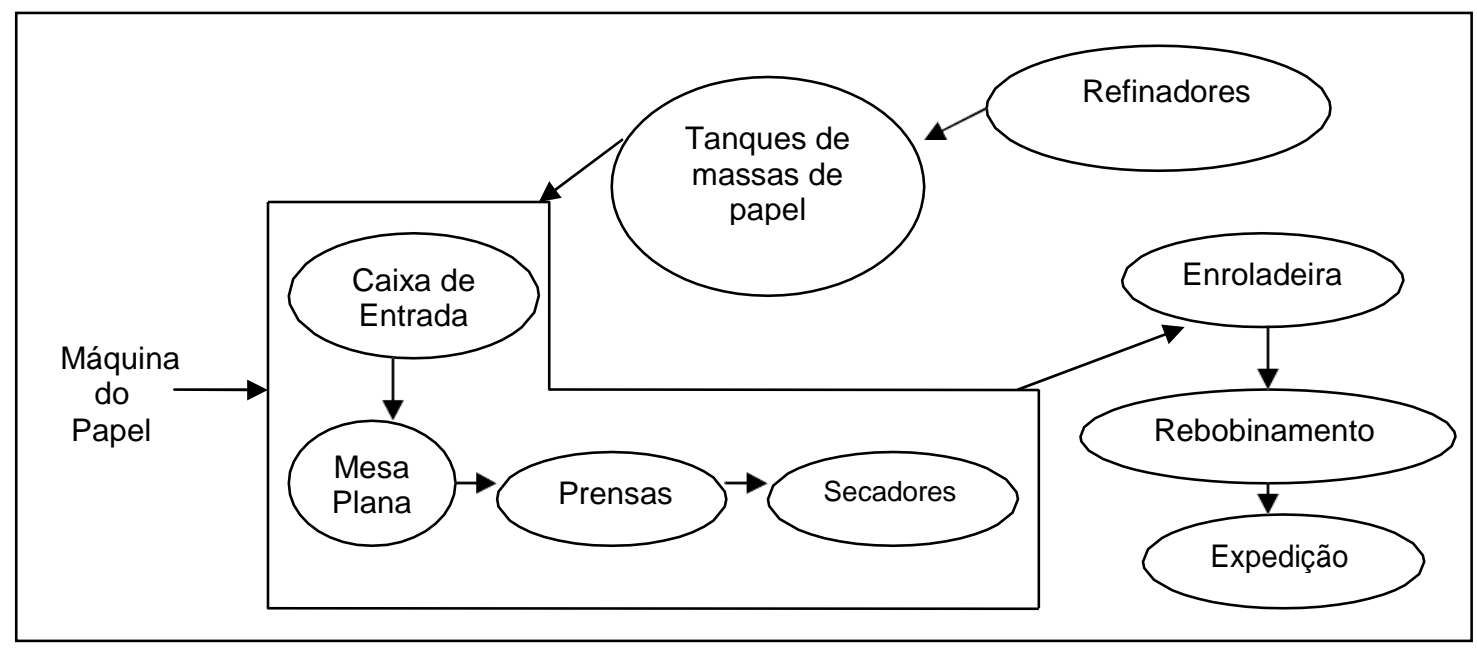

Figura 4 - Transformação do papel ondulado reciclado

Fonte: dados da pesquisa. 
$\mathrm{Na}$ última fase do processo de fabricação do papel ondulado reciclado, após a refinação, a suspensão fibrosa segue para os tanques de estocagem da máquina de papel. A máquina de papel é composta das seguintes partes:

Caixa de entrada - equipamento que recebe a massa depurada e distribui uniformemente sobre a mesa plana; e

Mesa plana - equipamento composto de uma tela e caixas de vácuo que tem a finalidade de formar a folha de papel e remover parte da água utilizada na diluição da massa; depois de formada a folha de papel passa para a prensagem.

As prensas são equipamentos compostos por dois rolos, entre os quais há um ou dois feltros, por onde passa a folha de papel sob pressão. A finalidade desses equipamentos é a compactação da folha e também a remoção de parte da água contida na folha de papel. Após prensada, a folha de papel passa para os secadores da máquina de papel.

A fase de secagem é composta por um conjunto de rolos que são aquecidos com a injeção de vapor, sobre os quais passa a folha de papel. A finalidade desses rolos é remover a quantidade de água, ainda presente na folha de papel, deixando-a conforme as especificações ideais de umidade. Após a secagem total da folha de papel esta é enrolada na enroladeira.

A enroladeira é um equipamento composto de um rolo e braços pneumáticos, aos quais é preso um rolo de diâmetro pequeno chamado estanga. Na estanga é enrolada a folha de papel que está sendo produzida. Após enrolado, o papel está pronto em uma forma bruta.

O rebobinamento é um equipamento composto de rolos e facas e que tem a finalidade de receber o rolo de papel bruto e cortá-lo em larguras diversas, conforme a necessidade ou especificação do pedido. De cada lado do rolo bruto corta-se uma tira de papel, chamada refile, dando o acabamento final ao produto.

Por último, após rebobinado, o papel é pesado e identificado e fica disponível 
para ser expedido se estiver dentro das especificações necessárias de qualidade. As especificações abrangem os seguintes requisitos: gramatura, rigidez, umidade e cobb (quantidade de água que o papel após acabado pode absorver).

Dois aspectos destacados na literatura e páginas eletrônicas pesquisadas sobre questões ambientais são observados nesta descrição: elevado consumo de energia e água ao longo do processo e a presença intensa de tecnologia para o processamento da matéria-prima. De acordo com o WBCSD (1996), a produção de papel consome enorme quantidade de energia e água. A ABTCP (2004) ressalta que a indústria de papel e celulose tem investido em tecnologia de reutilização das águas, o que contribui para o gerenciamento do ciclo de água e reduzir a geração de efluentes.

\subsection{Tratamento dado pela indústria aos resíduos e à preservação do meio ambiente}

A empresa objeto de estudo busca trabalhar dentro de padrões que permitam o desenvolvimento da atividade e minimizem a agressão ao meio ambiente. Procura preservar a atmosfera, hidrosfera e a litosfera, com utilização de tecnologia adequada. De acordo com o entrevistado, também procura estar de acordo com a legislação, atendendo às exigências referentes à qualidade da água, solo e gás.

No processo de fabricação do papel reciclado a empresa utiliza $60 \%$ da água do Rio do Peixe, aproveitando uma fonte natural desse recurso. Após passar pelo processo de produção do papel reciclado, a água é encaminhada para um primeiro filtro, que tem uma peneira. Este filtro é responsável pela retirada dos resíduos pesados (prego, arames, lâminas, etc). Em seguida esta água passa por um segundo filtro, que possui uma peneira mais fina que o primeiro, ficando neste os resíduos mais leves.

Passando pelos filtros, a água é encaminhada para um tanque e recebe tratamento adequado para que volte a tornar-se água potável. Posteriormente, 10\% desta água volta para o Rio do Peixe e o restante retorna para o processo de fabricação do papel. Isto é, quase a totalidade da água retorna ao processo fabril de papel. $\mathrm{Na}$ fundamentação teórica averiguou-se que a emissão de efluentes na água é um dos 
impactos ambientais mais significantes causados pela fabricação de papel e celulose, o que justifica o seu intenso cuidado na empresa.

Para assegurar a qualidade da água são monitorados os elementos que the conferem características de qualidade, como a demanda bioquímica de oxigênio (DBO), o oxigênio dissolvido (OD), indicador ácido base $(\mathrm{pH})$, temperatura, fenóis, óleos e graxas. A análise é realizada mensalmente pelo Serviço Nacional de Aprendizagem Industrial (SENAI/SC). Há ainda um intenso controle realizado pela polícia ambiental do município por meio de análise mensal da água que passa pelo Rio do Peixe e do lago do município em que é estocada a água que será tratada.

Os resíduos que foram retirados pelas peneiras e filtros passam por uma esteira, sendo encaminhados para segregar o material em aterros apropriados próprios, os quais possuem licenças ambientais aprovadas pela Fundação do Meio Ambiente (FATMA) e Instituto Brasileiro do Meio Ambiente e dos Recursos Naturais Renováveis (IBAMA).

Quanto ao gás, a empresa não agride o meio ambiente porque não tem forno de cal, caldeiras de recuperação e nem digestores industriais. Não emite os gases malcheirosos como: sulfeto de hidrogênio (H2S), metilsulfeto (MESH), dimetilsulfeto (Me2S) e dimetilsulfeto (ME2S2). Tal deve-se ao fato da empresa trabalhar com matériaprima reciclada, isto é, esse processo não resulta em liberação de gases dessa natureza.

Infere-se do exposto que, embora o setor de papel e celulose seja um setor altamente poluidor, conforme destacam Cormier e Magnan (1997 in Nossa e Carvalho, 2003), a empresa busca desenvolver suas atividades em conformidade com as exigências legais e à preservação sustentável. Apresenta menor impacto na extração de fibras florestais naturais porque utiliza material reciclado, que é um dos itens poluidores desta indústria apontados por Forgach (2001 in Nossa e Carvalho, 2003). Porém, dois itens poluidores apontados por esse autor, ainda que monitorados pela empresa, estão presentes nas suas atividades: a) exige uso intensivo de energia; e b) é grande produtora de resíduo sólido.

$\mathrm{Na}$ sequência, apresentam-se as ações executadas pela empresa objeto de 
estudo associadas às classificações dos custos ambientais (prevenção; avaliação ou detecção; falhas internas e falhas externas).

\subsection{Ações associadas aos custos ambientais executadas pela empresa}

Com o objetivo de identificar as ações associadas aos custos ambientais executadas pela empresa, se demonstra a partir da pesquisa teórica e empírica, as atividades relacionadas que são executadas e que não são executadas pela empresa objeto de estudo. As ações compreendem quatro categorias de custos: custos de prevenção ambiental, custos de deteç̧ão ou avaliação ambiental, custos de falhas ambientais internas e custos de falhas ambientais externas.

Para cada categoria de custos ambientais, com base na fundamentação teórica e na observação da realidade da empresa, foram listadas possíveis ações. A Tabela 1 apresenta as atividades executadas e não executadas na empresa no que se refere aos custos de prevenção ambiental.

Tabela 1 - Atividades de prevenção ambiental executadas e não executadas na empresa

\begin{tabular}{|c|c|c|}
\hline \multicolumn{3}{|c|}{ Custos de Prevenção Ambiental } \\
\hline Atividades de Prevenção & Executad & Não \\
\hline 1. Avaliar e selecionar fornecedores & $\mathrm{X}$ & \\
\hline 2. Avaliar e selecionar equipamentos de controle da poluição & $\mathrm{X}$ & $\mathrm{X}$ \\
\hline 3. Projetar processos para reduzir/eliminar os contaminadores & & \\
\hline 4. Treinar empregados & $\mathrm{X}$ & \\
\hline 5. Executar estudos ambientais & $\mathrm{X}$ & $\mathrm{X}$ \\
\hline 6. Auditar riscos ambientais & & $\mathrm{X}$ \\
\hline 7. Executar pesquisas ambientais & $\mathrm{X}$ & $\mathrm{X}$ \\
\hline 8. Desenvolver sistemas de gestão ambiental & & $\mathbf{4}$ \\
\hline R. Reciclar produtos & 6 & $\mathbf{4 0 \%}$ \\
\hline 10. Obter certificado ISO 14001 & $60 \%$ & \\
\hline Total &
\end{tabular}

Fonte: dados da pesquisa.

Verifica-se que a empresa realiza $60 \%$ das atividades de prevenção listadas, entre elas a avaliação e seleção dos fornecedores e dos equipamentos de controle da poluição, o treinamento intensivo dos empregados, a prática de auditorias ambientais e a reciclagem de produtos. Entretanto, não projeta processos para reduzir/eliminar os 
contaminadores, não executa pesquisas ambientais e nem utiliza um sistema de gestão ambiental. Foi ressaltado pelo entrevistado que a empresa pretende obter o certificado ISO 14001 nos próximos anos.

A Tabela 2 apresenta as atividades executadas e não executadas na empresa no que se refere aos custos de detecção ou avaliação ambiental.

Tabela 2 - Atividades de detecção ambiental executadas e não executadas na empresa

\begin{tabular}{|c|c|c|}
\hline \multicolumn{3}{|l|}{ Custos de Deteccão Ambiental } \\
\hline Atividades de Detecção ou Avaliação & Executad & Não \\
\hline $\begin{array}{l}\text { 1. Auditar atividades ambientais } \\
\text { 2. Inspecionar produtos e processos (conformidade ambiental) } \\
\text { 3. Desenvolver medidas de desempenho ambiental } \\
\text { 4. Testar e medir níveis de contaminação }\end{array}$ & $X$ & $\mathrm{X}$ \\
\hline Total & 3 & 2 \\
\hline Percentual & $60 \%$ & $40 \%$ \\
\hline
\end{tabular}

Fonte: dados da pesquisa.

Percebe-se que a empresa realiza $60 \%$ das atividades de detecção ou avaliação ambiental listadas. Não realiza $40 \%$, pois não desenvolve medidas de desempenho ambiental e nem verifica o mesmo em seus fornecedores. A Tabela 3 apresenta as atividades executadas e não executadas na empresa no que se refere aos custos de falhas ambientais internas.

Tabela 3 - Atividades de falhas ambientais internas executadas e não executadas na empresa

\begin{tabular}{|c|c|c|c|}
\hline \multicolumn{4}{|c|}{ Custos de Falhas Ambientais Internas } \\
\hline & Atividades de Falhas Internas & Executad & Não \\
\hline 1. & Operar equipamentos de controle da poluição & & $\mathrm{X}$ \\
\hline 2. & Tratar e descartar materiais tóxicos & $\mathrm{X}$ & \\
\hline 3. & Manter equipamento de poluição & & $\mathrm{X}$ \\
\hline 4. & Licenciar instalações para produzir contaminantes & & $\mathrm{X}$ \\
\hline 5. & Reciclar sucatas & $\mathrm{X}$ & \\
\hline 6. & Incorrer em retrabalho em processos por não-conformidade & & \\
\hline & ambiental & & $\mathrm{X}$ \\
\hline & Total & 2 & 4 \\
\hline & Percentual & $33,33 \%$ & $66,67 \%$ \\
\hline
\end{tabular}

Fonte: dados da pesquisa.

De um total de seis atividades possíveis, nota-se que a empresa não realiza 
$66,67 \%$ das atividades de falhas ambientais internas listadas. Executa apenas o tratamento e o descarte de materiais tóxicos e a reciclagem de sucatas. A Tabela 4 apresenta as atividades executadas e não executadas na empresa no que se refere aos custos de falhas ambientais externas, realizados e não-realizados (sociais).

Tabela 4 - Atividades de falhas ambientais externas executadas e não executadas na empresa

\begin{tabular}{|c|c|c|c|}
\hline \multicolumn{4}{|c|}{ Custos de Falhas Ambientais Externas } \\
\hline \multicolumn{2}{|r|}{ Atividades - Custos Realizados } & Executad & Não \\
\hline 1. & Limpar um rio ou lago poluído & & $\mathrm{X}$ \\
\hline 2. & Limpar o solo contaminado & & $\mathrm{X}$ \\
\hline 3. & Indenizar dados pessoais (relacionados ao meio ambiente) & & $\mathrm{X}$ \\
\hline 4. & Restaurar a terra ao estado natural & $\mathrm{X}$ & \\
\hline 5. & Perder vendas devido à má reputação ambiental & & X \\
\hline 6. & Usar materiais e energia ineficientemente & & $\mathrm{X}$ \\
\hline & Total & 1 & 5 \\
\hline & Percentual & $16,67 \%$ & $83,33 \%$ \\
\hline & Atividades - Custos Não-Realizados & Executad & Não \\
\hline 1. & Receber cuidados médicos devido a ar poluído & & $\mathrm{X}$ \\
\hline 2. & Perder emprego devido à contaminação & & $\mathrm{X}$ \\
\hline 3. & Perder um rio ou lago de uso recreativo & & $\mathrm{X}$ \\
\hline 4. & Danificar ecossistemas com o descarte de resíduos sólidos & & $\mathrm{X}$ \\
\hline & Total & $\mathbf{0}$ & 4 \\
\hline & Percentual & $0 \%$ & $100 \%$ \\
\hline
\end{tabular}

Fonte: dados da pesquisa.

Entre as 10 atividades de falhas ambientais externas listadas, sejam elas relacionadas aos custos realizados ou não-realizados, a empresa executa apenas a atividade de restaurar a terra ao estado natural. Ou seja, $83,33 \%$ das atividades listadas relacionadas aos custos realizados e $100 \%$ das atividades relacionadas aos custos nãorealizados não são executadas na empresa.

Diante do exposto, pode-se observar que a empresa analisada prioriza os custos de detecção e prevenção ambiental, minimiza a ocorrência das falhas relacionadas ao processo produtivo e ao meio ambiente. Tal atitude da empresa encontra suporte na teoria. Conforme Graedel e Allenby (1996) e Hansen e Mowen (2001), a abordagem próativa, baseada na prevenção de danos ambientais, pode ser menos onerosa que os custos ambientais de falhas internas e externas. 
Ressalta-se que a pesquisa limitou-se à coleta de dados qualitativos para identificação das ações executadas pela empresa referente às classificações dos custos ambientais, não adentrando nos valores empregados na execução das atividades de prevenção, detecção e de falhas internas e externas. A estratégia de pesquisa utilizada deve-se ao fato de muitos destes custos serem intangíveis, portanto de difícil mensuração.

\section{CONSIDERAÇÕES FINAIS}

O artigo objetivou descrever o processo de fabricação de papel reciclado e identificar ações associadas aos custos ambientais executadas pela empresa. Para tanto, realizou-se um estudo exploratório, por meio de um estudo de caso em indústria estabelecida no Estado de Santa Catarina, com abordagem qualitativa dos dados.

No que concerne ao processo de fabricação de papel reciclado, este foi segmentado em três fluxos de operações. Primeiro demonstraram-se as operações de fabricação desde a desagregação do papel velho até a transformação da massa. No segundo fluxo evidenciou-se a transformação dos resíduos da indústria da madeira e papel reciclado em massa e hidratação das fibras. No terceiro fluxo mostrou-se a transformação do papel ondulado reciclado.

Como resultado da pesquisa tem-se que o processo de fabricação de papel reciclado inicia com a adição das matérias-primas, passa pela desagregação e refinação da massa, segue para a suspensão fibrosa e finaliza com a secagem e rebobinamento do papel. Com relação ao tratamento dado pela empresa à matéria-prima reciclada, observou-se que esta utiliza tecnologia que the permite adequada gestão dos recursos ambientais. No entanto, mesmo que siga padrões que visam o desenvolvimento sustentável, procurando preservar a atmosfera, hidrosfera e a litosfera, e estar de acordo com a legislação, atendendo as exigências referentes à qualidade da água, solo e gás, é inerente à atividade o custo ambiental e social. 
Para assegurar a qualidade da água que retorna ao rio, o SENAI/SC monitora os elementos que lhe conferem essa característica. Os resíduos sólidos são encaminhados para segregar o material em aterros próprios, com licenças ambientais do IBAMA e FATMA. No que diz respeito ao gás, a empresa não agride o meio ambiente porque não tem forno de cal, caldeiras de recuperação e nem digestores industriais, portanto, não emite gases malcheirosos em decorrência de estar utilizando material reciclável.

Com relação às ações associadas aos custos ambientais, constatou-se que as ações executadas pela indústria são essencialmente de custos de detecção e prevenção ambiental. Sua ação pró-ativa à gestão de custos ambientais é promitente em termos de prevenção de danos ambientais e, conseqüentemente, em redução de custos. Sendo assim, a atitude da empresa encontra suporte na literatura, que afirma que a abordagem pró-ativa, baseada na prevenção de danos ambientais, pode ser menos onerosa que os custos ambientais de falhas internas e externas.

Conclui-se que o tratamento dado ao papel reciclado pela indústria de reciclagem contribui para a preservação ambiental, uma vez que quase sua totalidade retorna ao processo fabril de papel sob forma de matéria-prima. Tal fato tem suporte nos fundamentos teóricos apresentados, que caracterizam a indústria de papel e celulose como moderada geradora de resíduos sólidos de baixo poder impactante e elevada potencialidade de utilização. No entanto, é inerente à atividade um elevado consumo de energia e de água, caranterizando-a como altamente poluidora sob esse aspecto.

Consideradas as limitações da pesquisa realizada, recomenda-se para futuros estudos investigar se o processo de fabricação de papel reciclado e as ações executadas pela empresa associadas aos custos ambientais ocorrem de forma semelhante em indústrias congêneres. Sugere-se, também, pesquisar os valores monetários das diferentes categorias de custos ambientais utilizando-se da estratégia de pesquisa participante. 


\section{REFERÊNCIAS}

ANDRADE, R. O. B.; TACHIZAWA, T. e CARVALHO, A. B. (2002). Gestão ambiental: enfoque estratégico aplicado ao desenvolvimento sustentável. São Paulo, Makron Books, (2 ed.). 206 p.

Associação Brasileira de celulose e papel - BRACELPA. (1998). Considerações gerais sobre a atividade de reciclagem de papel no Brasil. São Paulo, BRACELPA. Palestra, III Seminário de Avaliação de Experiências Brasileiras de Coleta Seletiva de Lixo, 14p.

Associação Brasileira técnica de celulose e papel- ABTCP. (2004). Disponível em: http://www.abctp.org.br. Acesso em 05/agosto/2006.

BARDIN, L. (2006). Análise de conteúdo. Lisboa, Edições 70. (3 ed.). 225 p.

BELLIA, V. (1996). Introdução a economia do meio ambiente. Brasília, Ibama, 262 p.

CAMPOS, L. M. S. (1996). Um estudo para definição e identificação dos custos da qualidade ambiental. Dissertação de mestrado em Engenharia da Produção. Universidade Federal de Santa Catarina. Florianópolis, 104 p.

CERVO, A. e BERVIAN, A. (1996). Metodologia científica: para uso dos estudantes universitários. São Paulo, McGraw-Hill do Brasil. (4 ed.). 209 p.

Departamento de assistência à média e a pequena indústria - DETEC. (1989). Gerenciamento de resíduos em complexos integrados de papel e celulose. Rio de Janeiro, CNI, DAMPI. Convenio CNI- SESI/DN e SENAI/DN. 39p.

DUARTE, M. D. (1997). Caracterização da rotulagem ambiental de produtos. (Dissertação de mestrado). Universidade Federal de Santa Catarina - UFSC, Florianópolis. Disponível em: http://www.eps.ufsc.br/disserta97/duarte/biblio.html. Acesso em: 08/agosto/2006.

FACHIN, O. (2001). Fundamentos de metodologia. São Paulo, Saraiva. (3 ed.). 200 p.

Federação e Centro das Indústrias do Estado de São Paulo - FIESP. (2004). Cartilha de indicadores de desempenho ambiental na indústria. São Paulo, FIESP/CIESP, jun. 29p. Disponível em: http://www.fiesp.com.br/download/publicacoes_meio_ambiente/cartilha_indic_ambiental.p df. Acesso em: 08/agosto/2006.

FERREIRA, A. C. S.; BUFONI, A. L. e MUNIZ, N. P. (2007). Utilização do modelo ISAR/UNCTAD: uma análise comparativa. Pensar Contábil, 9(35):27-34. 
GOBBI, B. C. e BRITO, M. J. (2005). Gestão ambiental como prática social em uma organização produtora de celulose: uma análise interpretativa. In: ENANPAD, 29, Curitiba. Anais...Rio de Janeiro: ANPAD. CD-ROM.

GRAEDEL, T. E. e ALLENBY, B. R. (1996). Design for environment. Upper Saddle River, Prentice Hall, $175 \mathrm{p}$.

HANSEN, D. R. e MOWEN, M. M. (2001). Gestão de custos: contabilidade e controle. São Paulo, Pioneira Thompson Learning, $783 \mathrm{p}$.

HART, S.L. (1995). A natural-resource-based view of the firm. Academy of Management Review, v. 20, n. 4, p. 986-1014, oct.

HUNT, C. B. e AUSTER, E. R. (1990). Proactive environmental management: avoiding the toxic trap. Sloam Managenent Review, v. 31, n. 2, p. 7-18, winter.

NOSSA, V. e CARVALHO, L. N. G. (2003). Uma análise do conteúdo do disclosure ambiental de empresas do setor de papel e celulose em nível internacional. In: ENANPAD, 27, Salvador. Anais... Rio de Janeiro, ANPAD.

RIBEIRO, M.S. (1992). Contabilidade e meio ambiente. (Dissertação de mestrado). Universidade de São Paulo - USP, São Paulo, 141 p.

RIBEIRO, M. S. e ROCHA, W. (1999). Gestão estratégica dos custos ambientais. In: Congresso Brasileiro de Custos, 6, São Paulo, 1999. Anais...São Paulo: ABC, FEA/USP. CD-ROM.

RICHARDSON, R. J. (1999). Pesquisa social: métodos e técnicas. São Paulo, Atlas, (3 ed.). $389 \mathrm{p}$.

ROBLES Jr., A. (2003). Custos da qualidade: aspectos econômicos da gestão da qualidade e da gestão ambiental. São Paulo, Atlas. (2 ed.). 135 p.

ROSSATO, V. e RIBEIRO, M. S. (2004). Aplicação da contabilidade ambiental na indústria madeireira. Revista Contabilidade \& Finanças, n. 35, maio/ago. p. 54-67.

SILVA, H.V. (2007). Custos e proveitos ambientais: proposta de divulgação e relato na atividade de produção de eletricidade. Revista Universo Contábil, 3(2)116-124.

TRIVIÑOS, A.N.S. (1987). Introdução à pesquisa em ciências sociais: A pesquisa qualitativa em educação. São Paulo, Atlas, 175 p. 
World business council for sustainable development - WBCSD. (1996). Um futuro em transformação para o papel: seu impacto na sociedade e no meio ambiente, como a indústria do papel pode gerenciar estas mudanças, formas de tornar mais sustentável o ciclo do papel. Genebra, Suíça, WBCSD, il. Tradução de: Towards a sustainable paper cycle, $31 \mathrm{p}$.

YIN, R.K. (2003). Estudo de caso: planejamento e métodos. São Paulo, Bookman, 254 p.

Data de Submissão: 18/11/2007

Data de Aceite: 15/04/2008 